\title{
Microtubule minus-end regulation at a glance
}

\author{
Anna Akhmanova ${ }^{1, *}$ and Michel O. Steinmetz ${ }^{2,3, *}$
}

\begin{abstract}
Microtubules are cytoskeletal filaments essential for numerous aspects of cell physiology. They are polarized polymeric tubes with a fast growing plus end and a slow growing minus end. In this Cell Science at a Glance article and the accompanying poster, we review the current knowledge on the dynamics and organization of microtubule minus ends. Several factors, including the $\gamma$-tubulin ring complex, CAMSAP/Patronin, ASPM/Asp, SPIRAL2 (in plants) and the KANSL complex recognize microtubule minus ends and regulate their nucleation, stability and interactions with partners, such as microtubule severing enzymes, microtubule depolymerases and protein scaffolds. Together with minus-end-directed motors, these
\end{abstract}

${ }^{1}$ Cell Biology, Department of Biology, Faculty of Science, Utrecht University, Padualaan 8, $3584 \mathrm{CH}$ Utrecht, The Netherlands. ${ }^{2}$ Laboratory of Biomolecular Research, Division of Biology and Chemistry, Paul Scherrer Institut, CH-5232 Villigen PSI, Switzerland. ${ }^{3}$ University of Basel, Biozentrum, $\mathrm{CH}-4056$ Basel, Switzerland.

*Authors for correspondence (a.akhmanova@uu.nl; michel.steinmetz@psi.ch)

(D) A.A., 0000-0002-9048-8614; M.O.S., 0000-0001-6157-3687 microtubule minus-end targeting proteins (-TIPs) also control the formation of microtubule-organizing centers, such as centrosomes and spindle poles, and mediate microtubule attachment to cellular membrane structures, including the cell cortex, Golgi complex and the cell nucleus. Structural and functional studies are starting to reveal the molecular mechanisms by which dynamic -TIP networks control microtubule minus ends.

KEY WORDS: CAMSAP, Centrosome, Dynein, Gamma-tubulin ring complex, Microtubule, Spindle pole

\section{Introduction}

Microtubules are highly dynamic polymeric filaments that are required for a diverse array of essential cellular processes, such as cell division, motility and determination of cell shape. Microtubules participate in these functions by serving as scaffolds for organelle positioning and intracellular transport, and by exerting pulling and pushing forces on different subcellular structures. Microtubules assemble from dimers of $\alpha$ - and $\beta$-tubulin that align head-to-tail to form protofilaments, which associate laterally into tubes. This particular arrangement, together with the property that the

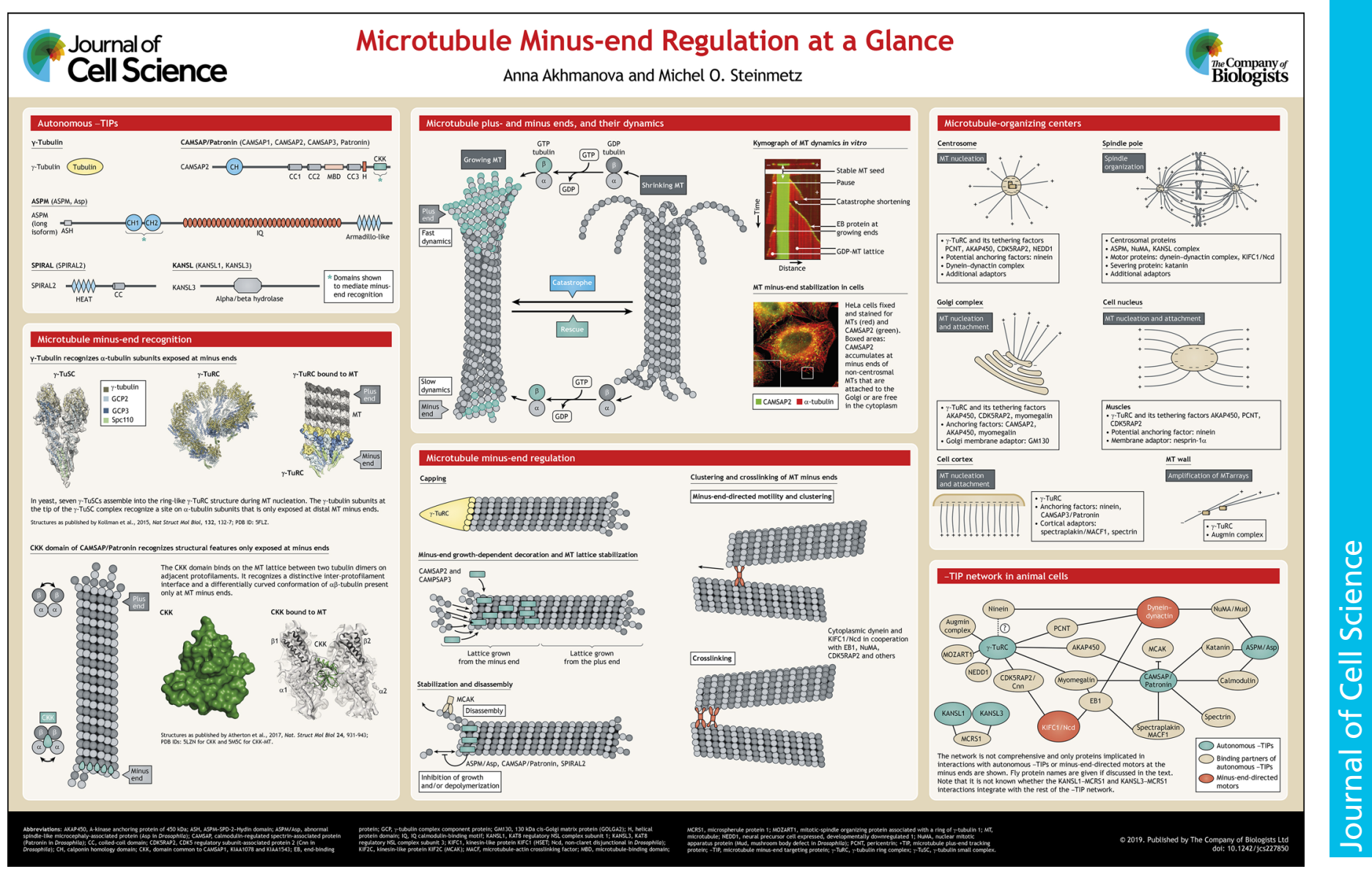


$\alpha \beta$-tubulin heterodimer is asymmetric, leads to the intrinsically polarized microtubule structure comprising two distinct ends (see poster). The end where $\alpha$-tubulin is exposed (termed the minus end) grows slowly in vitro, whereas the opposite end where $\beta$-tubulin faces into solution (termed the plus end) grows rapidly (Desai and Mitchison, 1997; Nogales and Wang, 2006). Both microtubule ends can switch between phases of growth and shrinkage, a process that depends on GTP hydrolysis on $\beta$-tubulin (Desai, and Mitchison, 1997). In cells, microtubule plus ends are responsible for the formation of the microtubule mass and for dynamic interactions with different subcellular structures. In contrast, the minus ends determine the geometry of microtubule networks because they are often stably anchored at sites where microtubules are nucleated (Akhmanova and Steinmetz, 2015; Martin and Akhmanova, 2018). A number of specific microtubule minus-end regulators have been identified. It is becoming increasingly clear that they represent a structurally and functionally diverse group of factors that control microtubule organization and, thus, play a crucial role in defining cell architecture. In this review and the accompanying poster, we provide an overview of the current knowledge on the structure, interactions and functions of cellular factors that specifically interact with microtubule minus ends, and that regulate their dynamics and organization.

\section{Structure and dynamics of microtubule minus ends}

Microtubule ends differ from the regular microtubule lattice in two main ways. First, the $\beta$-tubulin subunit of freshly added tubulin dimers is bound to GTP; such dimers form a stabilizing cap at both growing plus- and minus ends (referred to as 'GTP cap'; see poster). Within microtubule shafts, GTP is hydrolyzed to GDP, which leads to destabilization of the microtubule lattice and, eventually, to microtubule disassembly (Desai and Mitchison, 1997). Second, tubulin protofilaments at plus- and minus ends can have variable lengths and curvatures (Cross, 2019). Similar to plus ends, minus ends switch between periods of growth and shrinkage, albeit at slower rates. Minus ends can also exhibit pausing, a behavior that is not observed at plus ends in vitro (Doodhi et al., 2016; Erickson and O'Brien, 1992; Walker et al., 1988). In line with the higher stability of minus ends compared to that of plus ends, removal of the GTP cap by severing leads to the rapid disassembly of plus ends, whereas minus ends are more stable and can readily re-grow (Walker et al., 1989).

\section{Microtubule nucleation by the $\gamma$-tubulin ring complex and associated components}

Tubulin addition in cells occurs mainly at microtubule plus ends, whereas microtubule minus ends often remain associated with their original nucleation sites. One reason for this behavior is that the key microtubule nucleator, the $\gamma$-tubulin ring complex $(\gamma$-TuRC), caps microtubule minus ends by binding to their exposed $\alpha$-tubulin subunits (reviewed by Kollman et al., 2011; see poster).

In budding yeast, the ring-like $\gamma$-TuRC structure assembles during microtubule nucleation from $\gamma$-tubulin small complexes $(\gamma$-TuSCs) that contain the $\gamma$-tubulin complex component proteins 2 and 3 (GCP2 and GCP3, respectively) (Kollman et al., 2015; Kollman et al., 2010). In many other organisms, the $\gamma$-TuRC complex is preassembled by additional components, including the $\gamma$-tubulinbinding proteins GCP4, GCP5 and GCP6. GCPs associate with additional factors, such as Spc110 in yeast, and mitotic-spindle organizing protein associated with a ring of $\gamma$-tubulin 1 (MOZART1, officially referred to as MZT1) and neural precursor cell expressed, developmentally downregulated 1 (NEDD1) in mammals (reviewed by Tovey and Conduit, 2018). The microtubule-nucleating activity of $\gamma$-TuRC and its localization strongly depend on multiple tethering factors and adaptors, including the mammalian proteins pericentrin (PCNT), A-kinase anchoring protein of $450 \mathrm{kDa}$ (AKAP450, officially known as AKAP9), myomegalin and CDK5 regulatory subunit associated protein 2 (CDK5RAP2; Cnn in Drosophila (Tovey and Conduit, 2018). Association of these components with additional molecular scaffolds leads to the clustering of $\gamma$-TuRC complexes and microtubule regulators. This assembly process results in the formation of microtubule-organizing centers (MTOCs), such as animal centrosomes, fungal spindle pole bodies and related structures in other organisms (Ito and Bettencourt-Dias, 2018; see poster).

Another $\gamma$-TuRC-interacting component is the augmin (HAUS in mammals) complex, comprising eight protein subunits and mediating microtubule nucleation from the lateral surfaces of preexisting microtubules (Petry et al., 2013; Song et al., 2018). Augmin participates in amplification of parallel microtubule arrays in mitotic spindles, neurons and at the cortex of plant cells (Cunha-Ferreira et al., 2018; Goshima et al., 2008; Sánchez-Huertas et al., 2016; Sánchez-Huertas and Luders, 2015; Yi and Goshima, 2018).

\section{Proteins specifically targeting free microtubule minus ends}

$\gamma$-TuRC blocks the exchange of tubulin dimers at minus ends (Wiese and Zheng, 2000); however, not all microtubule minus ends in cells are capped. For example, spindle microtubules slowly disassemble at the minus ends and elongate at the plus ends, a process that leads to the poleward flux of microtubule polymers (Borgal and Wakefield, 2018; Rogers et al., 2005). In interphase, the disassembly of free microtubule minus ends contributes to the turnover of radial centrosomal microtubule arrays (Rodionov et al., 1999).

A number of proteins can interact with dynamic microtubule minus ends and affect their stability; together with $\gamma$-TuRC, such specific minus-end targeting proteins were termed -TIPs (Akhmanova and Hoogenraad, 2015). Among these, the members of the calmodulin-regulated spectrin-associated protein (CAMSAP) family in mammals and Patronin in invertebrates have recently received substantial attention (see poster). The ability of these proteins to recognize microtubule minus ends depends on their C-terminal domain common to CAMSAP1, KIAA1078 and KIAA1543 (CKK); however, an autonomous minus-end tracking activity has also been observed for a coiled-coil region of Drosophila Patronin (Hendershott and Vale, 2014; Jiang et al., 2014; Atherton et al., 2017). Depending on the family member, CAMSAP/Patronin proteins either track growing microtubule minus ends (CAMSAP1), bind to minus ends to inhibit their growth (Drosophila Patronin), or specifically bind to lattice stretches formed by minus-end growth (CAMSAP2 and CAMSAP3) (Hendershott and Vale, 2014; Jiang et al., 2014). While the function of CAMSAP1 is still not clear, CAMSAP2 and CAMSAP3 slow down but do not block minus-end polymerization and form stabilized microtubule stretches that can promote repeated plus-end outgrowth (Hendershott and Vale, 2014; Jiang et al., 2014). CAMSAPs thus stabilize microtubule ends in a manner dependent on minus-end polymerization (Jiang et al., 2014). Whether microtubule minus-end stabilization by Patronin is associated with some tubulin addition at the minus end is currently unclear. In worms and mammals, the activity of CAMSAPs is mainly important for generating non-centrosomal microtubule arrays in differentiated interphase cells, such as epithelial cells or neurons, whereas in Drosophila, Patronin regulates minus-end stability both in interphase and mitosis (Chuang et al., 2014; Derivery et al., 2015; 
Goodwin and Vale, 2010; Jiang et al., 2014; Marcette et al., 2014; Nashchekin et al., 2016; Richardson et al., 2014; Tanaka et al., 2012; Toya et al., 2016; Wang et al., 2013; Yau et al., 2014).

Another protein that can autonomously recognize dynamic microtubule minus ends and inhibit their growth is abnormal spindle-like microcephaly-associated protein (ASPM; Asp in Drosophila) (Jiang et al., 2017) (see poster). It localizes to spindle poles and is required for spindle organization, spindle positioning and cytokinesis (Higgins et al., 2010; Saunders et al., 1997; van der Voet et al., 2009; Wakefield et al., 2001). For example, in Drosophila, Asp is essential for spindle pole focusing, likely due to its microtubule minus-end binding and crosslinking activities (Ito and Goshima, 2015; Schoborg et al., 2015). In mammals, ASPM affects spindle architecture in more subtle ways, as its activity appears to be somewhat redundant with centrosomal components (Higgins et al., 2010; Jiang et al., 2017; Tungadi et al., 2017). ASPM has been intensively studied because it is encoded by a gene that is frequently mutated in microcephaly, a human brain development disorder (Bond et al., 2002).

Completely different minus-end regulators in vertebrates are components of an interphase chromatin-associated protein complex termed KANSL that contains the KAT8 regulatory NSL complex subunits 1 and 3 (KANSL1 and KANSL3), which can recognize the minus ends of stabilized microtubules (Meunier et al., 2015). The KANSL complex contains another factor, the microspherule protein 1 (MCRS1), which shows no minus-end preference on its own but participates in spindle formation by promoting minus-end stability of kinetochore fibers (Meunier et al., 2015; Meunier and Vernos, 2011). The activity of the KANSL complex on dynamic minus ends in vitro has not yet been described.

Plants express the microtubule minus-end regulator SPIRAL2 that is structurally unrelated to the -TIPs described above. This protein autonomously recognizes minus ends, slows down minusend depolymerization in plant cells and inhibits minus-end dynamics in vitro (Fan et al., 2018; Leong et al., 2018; Nakamura et al., 2018). SPIRAL2 also binds to plus ends and affects their dynamics, but this interaction possibly depends on additional binding partners (Fan et al., 2018).

\section{Minus-end regulators that can interact with both microtubule ends}

In addition to the specific minus-end regulators discussed above, a number of proteins show association with both microtubule ends. End-binding (EB; MAPRE) proteins, for example, are classified as microtubule plus-end tracking proteins (+TIPs) based on their localization behavior in cells; however, in vitro, EBs autonomously track growing microtubule plus- and minus ends, because they show strong preference for the GTP or GDP-Pi cap (Bieling et al., 2007; Maurer et al., 2012; Zhang et al., 2015). The size of this cap decreases at low microtubule growth rates, and thus under physiological conditions, the actual minus-end accumulation of the EBs, as well as that of the numerous partners they can recruit to microtubule tips, is low (Akhmanova and Steinmetz, 2015).

Other proteins, such as members of the microtubule depolymerase kinesin-13 family or the microtubule-severing enzyme katanin, can show preference to microtubule ends possibly because of the increased protofilament curvature present at this location (Asenjo et al., 2013; Jiang et al., 2017). These proteins can either compete or cooperate with specific microtubule minus-end regulators (see poster). For example, the microtubule depolymerase activity of the members of the kinesin-13 family, such as the mitotic centromereassociated kinesin (MCAK; officially known as KIF2C), is counteracted by CAMSAP/Patronin as well as by the KANSL complex (Atherton et al., 2017; Goodwin and Vale, 2010; Meunier and Vernos, 2011). Katanin, on the other hand, can specifically bind to CAMSAPs and ASPM and cooperate with them by inhibiting microtubule minus-end growth (Jiang et al., 2014; Jiang et al., 2017).

Another important microtubule minus-end associated protein is the nuclear mitotic apparatus protein 1 (NUMA1, hereafter referred to as NuMA; known as mushroom body defect, Mud, in Drosophila), which acts in complex with cytoplasmic dynein and dynactin (Merdes et al., 1996). NuMA contains a microtubulebinding domain that associates with both microtubule plus- and minus ends in vitro (Seldin et al., 2016). In mitotic cells, NuMA can be recruited to freshly severed microtubule minus ends independently of dynein and other known mitotic minus-end regulators and plays a key role in focusing microtubule minus ends at spindle poles (Hueschen et al., 2017). The origin of the microtubule minus-end preference of NuMA is currently unclear.

\section{Minus-end directed motors in microtubule organization}

Microtubule minus-end directed motors, cytoplasmic dynein and members of the kinesin-14 family, such as kinesin expressed in human spleen, embryo and testes (HSET) - officially known as kinesin family member $\mathrm{C} 1$ (KIFC1) in mammals and non-claret disjunctional (Ncd) in Drosophila - are targeted to minus ends due to their minus-end-directed motor activity (She and Yang, 2017; Tan et al., 2018 and references therein). In cooperation with additional proteins, such as NuMA, EB1 or CDK5RAP2 (Chavali et al., 2016; Goshima et al., 2005; Merdes et al., 1996), these motors can cluster and crosslink microtubule minus ends, an activity that is essential for the formation of a bipolar spindle during cell division (reviewed by Borgal and Wakefield, 2018; Hentrich and Surrey, 2010; Maiato and Logarinho, 2014; Tan et al., 2018). Furthermore, cytoplasmic dynein can bind to different MTOC components involved in microtubule nucleation and anchoring, such as PCNT or ninein (Purohit et al., 1999; Redwine et al., 2017). By doing so, dynein concentrates these factors in the vicinity of minus ends and thereby promotes MTOC formation (Balczon et al., 1999; Burakov et al., 2008; Hori and Toda, 2017).

\section{Mechanisms of specific microtubule minus-end recognition}

In contrast to proteins that interact with both microtubule ends, our understanding of specific minus-end binders is much less advanced. These proteins are supposed to recognize structural features that are only present at minus ends and not at plus ends. One such prominent feature that is only exposed at minus ends is the surface of $\alpha$-tubulin, which is involved in longitudinal tubulin-tubulin interactions along protofilaments. This surface is recognized by the $\gamma$-tubulin subunits of the $\gamma$-TuRC complex, which readily explains the specificity of the $\gamma$-TuRC towards minus ends (reviewed by Kollman et al., 2011; see poster).

Microtubule plus ends are also distinguished from the minus ends by the distinctive interactions that $\alpha$ - and $\beta$-tubulin subunits establish across adjacent protofilament as a result of the polar head-to-tail arrangement of curved $\alpha \beta$-tubulin dimers (reviewed by Brouhard and Rice, 2014). These structural features (i.e. distinct nature of the inter-protofilament interface and the characteristic curvature of protofilaments) are recognized by the globular CKK domain of CAMSAP/Patronin family members, which binds between two tubulin dimers from neighboring protofilaments at minus ends (Atherton et al., 2017) (see poster). The current model is that the tighter interaction of CKK with $\beta$-tubulin disfavors binding at microtubule plus ends, while the looser $\alpha$-tubulin contacts 
preferentially accommodate tubulin curvature at minus ends (Atherton et al., 2017). For other autonomous -TIPs, the mechanisms of minus-end recruitment are currently unknown due to lack of structural information.

\section{Microtubule minus-end anchoring to subcellular structures}

The most important activity of microtubule minus-end regulators is to form different types of MTOCs (see poster). Among these, the animal centrosome is the best-studied example. It is formed around a pair of microtubule-based cylinders called centrioles, which are surrounded by the pericentriolar matrix (PCM). In addition to $\gamma$-TuRC and various proteins that can tether and activate it, the PCM contains proteins that promote microtubule nucleation and growth, such as the microtubule polymerase colonic and hepatic tumor overexpressed gene [chTOG in mammals, officially known as CKAP5; also known as Xenopus microtubule-associated protein of $215 \mathrm{kDa}$ (XMAP215)]. PCM also contains microtubule-anchoring factors and proteins that act as a 'glue' between centrosomal components and bridge them to the centriole wall, such as PCNT, and CEP152 and CEP192 (asterless and Spd-2, respectively, in Drosophila) (in Drosophila) (reviewed by Conduit et al., 2015; Varadarajan and Rusan, 2018). Centrosomes are membrane-free organelles that can be regarded as condensates of PCM proteins that self-assemble around centrioles through multivalent interactions and concentrate tubulin to promote microtubule formation (Woodruff et al., 2017). At least in some cases, such as the very large mitotic centrosomes in worm embryos, where $\gamma$-TuRC was shown to be dispensable (Hannak et al., 2002), the function of centrosomes in concentrating proteins rather than the $\gamma$-TuRC activity might be key for microtubule nucleation (Woodruff et al., 2017). However, in order to from a radial plus-end-out microtubule array, enhanced microtubule nucleation at the centrosome must be accompanied by stable anchoring of newly generated minus ends. The biochemical basis of this process is still rather obscure. The $\gamma$-TuRC-tethering protein NEDD1 is one potential candidate involved in microtubule anchoring at centrosomes as it can tether minus ends to ectopic locations (Muroyama et al., 2016). Another protein frequently implicated in minus-end anchoring at both centrosomes and non-centrosomal sites is ninein (Goldspink et al., 2017; Kowanda et al., 2016; Mogensen et al., 2000; Wang et al., 2015); however, it is unclear whether ninein can recognize $\gamma$-TuRCbound or -free microtubule minus ends.

The same organizing principles likely apply to other MTOCs. For example, the Golgi membranes can recruit $\gamma$-TuRC and nucleate microtubules through a complex that consists of AKAP450 and CDK5RAP2 and/or myomegalin, but require a CAMSAP2AKAP450-myomegalin complex for minus-end anchoring (Rivero et al., 2009; Wu et al., 2016) (see poster). Importantly, even the combination of these two complexes is not sufficient for the MTOC function of the Golgi complex. Additional microtubulebinding proteins such as the +TIPs EBs and cytoplasmic linker associated proteins (CLASPs) are required to nucleate and tether microtubule minus ends at Golgi membranes (Efimov et al., 2007; Yang et al., 2017), suggesting that multiple weak interactions are involved in this process. In epithelial cells as well as in Drosophila oocytes, microtubule minus ends are tethered to the actin-rich cell cortex, and depending on the particular system, $\gamma$-TuRC-, ninein- or CAMSAP/Patronin-dependent complexes or combinations thereof have been reported (Goldspink et al., 2017; Khanal et al., 2016; Nashchekin et al., 2016; Noordstra et al., 2016; Toya et al., 2016; Wang et al., 2015). A network of $\gamma$-TuRC-binding factors and centrosomal proteins - including AKAP450, PCNT and ninein - participates in microtubule minus-end organization at the nuclear envelope of muscle cells (Bugnard et al., 2005; Gimpel et al., 2017; Tassin et al., 1985). Furthermore, in Drosophila oocytes $\gamma$-tubulin, Mud (NuMA homolog) and Asp participate in organizing the perinuclear MTOC (Januschke et al., 2006; Tissot et al., 2017). Other membrane organelles can also contribute to MTOC formation; for example, mitochondrial derivatives in Drosophila spermatids perform an MTOC function that is dependent on $\gamma$-TuRC and on a testis-specific non-centrosomal isoform of Cnn (CnnT; Chen et al., 2017). The presence of multicomponent complexes that form through multivalent interactions and exhibit properties of non-membrane-bound protein condensates or phase-separated, liquid droplets might be a general physicochemical feature of MTOCs, including spindle poles in animals (Borgal and Wakefield, 2018) or mitotic MTOCs, such as the polar caps and polar organizers in plants (Yi and Goshima, 2018).

\section{Drugs that can perturb microtubule minus ends}

Microtubule-targeting agents (MTAs) are among the most important drugs used to treat cancer. It is thought that at low, therapeutically relevant concentrations, MTAs primarily suppress microtubule dynamics by perturbing both microtubule plus- and minus ends (reviewed by Dumontet and Jordan, 2010). Dozens of different chemical classes of MTA are known, and six different tubulin-binding sites - and, accordingly, modes of action - have been described so far (reviewed by Steinmetz and Prota, 2018). Most MTAs target $\beta$-tubulin and are, thus, expected to perturb predominantly microtubule plus ends (e.g. paclitaxel, maytansine, eribulin). Other drugs bind simultaneously to both the $\alpha$ - and $\beta$-tubulin subunits, either within the tubulin dimer (e.g. colchicine, combretastatin) or in between two longitudinally aligned tubulin dimers (e.g. vinblastine, auristatin). The MTA pironetin, however, binds covalently to a cysteine residue of $\alpha$-tubulin and causes perturbations of secondary structure elements that are critically involved in longitudinal tubulin-tubulin interactions in microtubules (Prota et al., 2016; Yang et al., 2016). Pironetin, thus, potentially blocks microtubule minus-end growth by inhibiting the addition of tubulin dimers.

Another compound that can affect microtubule minus-end regulation is gatastatin, which binds to $\gamma$-tubulin and inhibits microtubule nucleation (Chinen et al., 2015). This property of gatastatin can be exploited in order to dissect the relative importance of $\gamma$-TuRC-dependent and -independent nucleation pathways; however, the interpretation of results in cells might be complicated by the fact that this compound also has some affinity for $\alpha \beta$-tubulin (Chinen et al., 2015).

\section{Perspectives}

Genetics and cell biology studies have led to the establishment of a list of -TIPs that control microtubule minus-end organization. However, biochemical and mechanistic studies of -TIPs are lagging behind - even our understanding of the structure and dynamics of microtubule minus ends is limited. Concerted studies have recently identified a number of autonomous -TIPs but this list is likely to be incomplete, especially if one takes into account that specific regulators can be represented by different isoforms with divergent properties. Furthermore, the structural basis of microtubule minus-end recognition, the activity of most of the known -TIPs, and how -TIPs and +TIPs cooperate to regulate microtubule minus ends still need to be defined and represent exciting new areas of future research.

It is also becoming increasingly clear that MTOCs are multicomponent structures formed by dynamic protein networks with multivalent and partially redundant interactions. The concept 
of 'phase separation', leading to the generation of liquid-like protein droplets or condensates, turned out to be helpful in describing and understanding the physicochemical principles of MTOC biogenesis (reviewed by Woodruff et al., 2018). Notably, recent work showed that many proteins easily undergo phase separation at high concentrations and in the presence of crowding agents (Woodruff et al., 2018). The current challenge is to assess the physiological relevance of such processes by systematically comparing in vivo and in vitro experiments, for example, by generating mutants that perturb specific interaction nodes within -TIP networks. The combination of biochemical reconstitutions, structural studies and cell biological assays that employ genetic modifications of -TIPs will eventually lead to a comprehensive understanding of this essential aspect of cell architecture.

\section{Acknowledgements}

We thank Carolyn Moores and Joseph Atherton (Birkbeck University of London, UK), and Ruddi Rodriguez-Garcia, Shasha Hua and Kai Jiang (formerly A.A.'s laboratory, Utrecht University, The Netherlands) for preparing images shown on poster

\section{Funding}

A.A. is supported by the European Research Council Synergy grant 609822. M.O.S. is supported by the Swiss National Science Foundation grant 31003A_166608.

\section{References}

Akhmanova, A. and Hoogenraad, C. C. (2015). Microtubule minus-end-targeting proteins. Curr. Biol. 25, R162-R171. doi:10.1016/j.cub.2014.12.027

Akhmanova, A. and Steinmetz, M. O. (2015). Control of microtubule organization and dynamics: two ends in the limelight. Nat. Rev. Mol. Cell Biol. 16, 711-726. doi:10.1038/nrm4084

Asenjo, A. B., Chatterjee, C., Tan, D., DePaoli, V., Rice, W. J., Diaz-Avalos, R., Silvestry, M. and Sosa, H. (2013). Structural model for tubulin recognition and deformation by kinesin-13 microtubule depolymerases. Cell Rep. 3, 759-768. doi:10.1016/j.celrep.2013.01.030

Atherton, J., Jiang, K., Stangier, M. M., Luo, Y., Hua, S., Houben, K., van Hooff, J. J. E., Joseph, A.-P., Scarabelli, G., Grant, B. J. et al. (2017). A structural model for microtubule minus-end recognition and protection by CAMSAP proteins. Nat. Struct. Mol. Biol. 24, 931-943. doi:10.1038/nsmb.3483

Balczon, R., Varden, C. E. and Schroer, T. A. (1999). Role for microtubules in centrosome doubling in Chinese hamster ovary cells. Cell Motil. Cytoskeleton 42 60-72. doi:10.1002/(SICl)1097-0169(1999)42:1<60\%:AID-CM6>3.0.CO;2-7

Bieling, P., Laan, L., Schek, H., Munteanu, E. L., Sandblad, L., Dogterom, M., Brunner, D. and Surrey, T. (2007). Reconstitution of a microtubule plus-end tracking system in vitro. Nature 450, 1100-1105. doi:10.1038/nature06386

Bond, J., Roberts, E., Mochida, G. H., Hampshire, D. J., Scott, S., Askham, J. M., Springell, K., Mahadevan, M., Crow, Y. J., Markham, A. F. et al. (2002). ASPM is a major determinant of cerebral cortical size. Nat. Genet. 32, 316-320. doi:10. 1038/ng995

Borgal, L. and Wakefield, J. G. (2018). Context-dependent spindle pole focusing Essays Biochem. 62, 803-813. doi:10.1042/EBC20180034

Brouhard, G. J. and Rice, L. M. (2014). The contribution of alphabeta-tubulin curvature to microtubule dynamics. J. Cell Biol. 207, 323-334. doi:10.1083/jcb. 201407095

Bugnard, E., Zaal, K. J. M. and Ralston, E. (2005). Reorganization of microtubule nucleation during muscle differentiation. Cell Motil. Cytoskeleton 60, 1-13. doi:10. $1002 / \mathrm{cm} .20042$

Burakov, A., Kovalenko, O., Semenova, I., Zhapparova, O., Nadezhdina, E. and Rodionov, V. (2008). Cytoplasmic dynein is involved in the retention of microtubules at the centrosome in interphase cells. Traffic 9, 472-480. doi:10. 1111/j.1600-0854.2007.00698.x

Chavali, P. L., Chandrasekaran, G., Barr, A. R., Tátrai, P., Taylor, C., Papachristou, E. K., Woods, C. G., Chavali, S. and Gergely, F. (2016). A CEP215-HSET complex links centrosomes with spindle poles and drives centrosome clustering in cancer. Nat. Commun. 7, 11005. doi:10.1038/ ncomms11005

Chen, J. V., Buchwalter, R. A., Kao, L. R. and Megraw, T. L. (2017). A splice variant of centrosomin converts mitochondria to microtubule-organizing centers. Curr. Biol. 27, 1928-1940 e6. doi:10.1016/j.cub.2017.05.090

Chinen, T., Liu, P., Shioda, S., Pagel, J., Cerikan, B., Lin, T. C., Gruss, O., Hayashi, Y., Takeno, H., Shima, T. et al. (2015). The gamma-tubulin-specific inhibitor gatastatin reveals temporal requirements of microtubule nucleation during the cell cycle. Nat. Commun. 6, 8722. doi:10.1038/ncomms9722
Chuang, M., Goncharov, A., Wang, S., Oegema, K., Jin, Y. and Chisholm, A. D. (2014). The microtubule minus-end-binding protein patronin/PTRN-1 is required for axon regeneration in C. elegans. Cell Rep. 9, 874-883. doi:10.1016/j.celrep. 2014.09.054

Conduit, P. T., Wainman, A. and Raff, J. W. (2015). Centrosome function and assembly in animal cells. Nat. Rev. Mol. Cell Biol. 16, 611-624. doi:10.1038/ nrm4062

Cross, R. A. (2019). Microtubule lattice plasticity. Curr. Opin. Cell Biol. 56, 88-93. doi:10.1016/j.ceb.2018.10.004

Cunha-Ferreira, I., Chazeau, A., Buijs, R. R., Stucchi, R., Will, L., Pan, X., Adolfs, Y., van der Meer, C., Wolthuis, J. C., Kahn, O. I. et al. (2018). The HAUS complex is a key regulator of non-centrosomal microtubule organization during neuronal development. Cell Rep. 24, 791-800. doi:10.1016/j.celrep.2018.06.093

Derivery, E., Seum, C., Daeden, A., Loubéry, S., Holtzer, L., Jülicher, F. and Gonzalez-Gaitan, M. (2015). Polarized endosome dynamics by spindle asymmetry during asymmetric cell division. Nature 528, 280-285. doi:10.1038/ nature16443

Desai, A. and Mitchison, T. J. (1997). Microtubule polymerization dynamics. Annu. Rev. Cell Dev. Biol. 13, 83-117. doi:10.1146/annurev.cellbio.13.1.83

Doodhi, H., Prota, A. E., Rodríguez-Garcia, R., Xiao, H., Custar, D. W., Bargsten, K., Katrukha, E. A., Hilbert, M., Hua, S., Jiang, K. et al. (2016). Termination of protofilament elongation by eribulin induces lattice defects that promote microtubule catastrophes. Curr. Biol. 26, 1713-1721. doi:10.1016/j.cub.2016.04 053

Dumontet, C. and Jordan, M. A. (2010). Microtubule-binding agents: a dynamic field of cancer therapeutics. Nat. Rev. Drug Discov. 9, 790-803. doi:10.1038/ $\operatorname{nrd} 3253$

Efimov, A., Kharitonov, A., Efimova, N., Loncarek, J., Miller, P. M., Andreyeva, N., Gleeson, P., Galjart, N., Maia, A. R., McLeod, I. X. et al. (2007). Asymmetric CLASP-dependent nucleation of noncentrosomal microtubules at the trans-Golgi network. Dev. Cell 12, 917-930. doi:10.1016/j.devcel.2007.04.002

Erickson, H. P. and O'Brien, E. T. (1992). Microtubule dynamic instability and GTP hydrolysis. Annu. Rev. Biophys. Biomol. Struct. 21, 145-166. doi:10.1146/ annurev.bb.21.060192.001045

Fan, Y., Burkart, G. M. and Dixit, R. (2018). The arabidopsis SPIRAL2 protein targets and stabilizes microtubule minus ends. Curr. Biol. 28, 987-994.e3. doi:10. 1016/j.cub.2018.02.014

Gimpel, P., Lee, Y. L., Sobota, R. M., Calvi, A., Koullourou, V., Patel, R. Mamchaoui, K., Nédélec, F., Shackleton, S., Schmoranzer, J. et al. (2017) Nesprin-1alpha-dependent microtubule nucleation from the nuclear envelope via Akap450 is necessary for nuclear positioning in muscle cells. Curr. Biol. 27 2999-3009. doi:10.1016/j.cub.2017.08.031

Goldspink, D. A., Rookyard, C., Tyrrell, B. J., Gadsby, J., Perkins, J., Lund, E. K., Galjart, N., Thomas, P., Wileman, T. and Mogensen, M. M. (2017). Ninein is essential for apico-basal microtubule formation and CLIP-170 facilitates its redeployment to non-centrosomal microtubule organizing centres. Open Biol. 7 160274. doi:10.1098/rsob.160274

Goodwin, S. S. and Vale, R. D. (2010). Patronin regulates the microtubule network by protecting microtubule minus ends. Cell 143, 263-274. doi:10.1016/j.cell.2010. 09.022

Goshima, G., Nédélec, F. and Vale, R. D. (2005). Mechanisms for focusing mitotic spindle poles by minus end-directed motor proteins. J. Cell Biol. 171, 229-240. doi:10.1083/jcb.200505107

Goshima, G., Mayer, M., Zhang, N., Stuurman, N. and Vale, R. D. (2008). Augmin: a protein complex required for centrosome-independent microtubule generation within the spindle. J. Cell Biol. 181, 421-429. doi:10.1083/jcb.200711053

Hannak, E., Oegema, K., Kirkham, M., Gönczy, P., Habermann, B. and Hyman, A. A. (2002). The kinetically dominant assembly pathway for centrosomal asters in Caenorhabditis elegans is gamma-tubulin dependent. J. Cell Biol. 157, 591-602. doi:10.1083/jcb.200202047

Hendershott, M. C. and Vale, R. D. (2014). Regulation of microtubule minus-end dynamics by CAMSAPs and Patronin. Proc. Natl. Acad. Sci. USA 111 5860-5865. doi:10.1073/pnas.1404133111

Hentrich, C. and Surrey, T. (2010). Microtubule organization by the antagonistic mitotic motors kinesin-5 and kinesin-14. J. Cell Biol. 189, 465-480. doi:10.1083/ jcb.200910125

Higgins, J., Midgley, C., Bergh, A.-M., Bell, S. M., Askham, J. M., Roberts, E., Binns, R. K., Sharif, S. M., Bennett, C., Glover, D. M. et al. (2010). Human ASPM participates in spindle organisation, spindle orientation and cytokinesis. BMC Cell Biol. 11, 85. doi:10.1186/1471-2121-11-85

Hori, A. and Toda, T. (2017). Regulation of centriolar satellite integrity and its physiology. Cell. Mol. Life Sci. 74, 213-229. doi:10.1007/s00018-016-2315-x

Hueschen, C. L., Kenny, S. J., Xu, K. and Dumont, S. (2017). NuMA recruits dynein activity to microtubule minus-ends at mitosis. Elife 6, e29328. doi:10.7554/ eLife. 29328

Ito, D. and Bettencourt-Dias, M. (2018). Centrosome remodelling in evolution Cells 7, E71. doi:10.3390/cells7070071

Ito, A. and Goshima, G. (2015). Microcephaly protein Asp focuses the minus ends of spindle microtubules at the pole and within the spindle. J. Cell Biol. 211 999-1009. doi:10.1083/jcb.201507001 
Januschke, J., Gervais, L., Gillet, L., Keryer, G., Bornens, M. and Guichet, A (2006). The centrosome-nucleus complex and microtubule organization in the Drosophila oocyte. Development 133, 129-139. doi:10.1242/dev.02179

Jiang, K., Hua, S., Mohan, R., Grigoriev, I., Yau, K. W., Liu, Q., Katrukha, E. A., Altelaar, A. F., Heck, A. J. R., Hoogenraad, C. C. et al. (2014). Microtubule minus-end stabilization by polymerization-driven CAMSAP deposition. Dev. Cell 28, 295-309. doi:10.1016/j.devcel.2014.01.001

Jiang, K., Rezabkova, L., Hua, S., Liu, Q., Capitani, G., Altelaar, A. F. M., Heck A. J. R., Kammerer, R. A., Steinmetz, M. O. and Akhmanova, A. (2017) Microtubule minus-end regulation at spindle poles by an ASPM-katanin complex Nat. Cell Biol. 19, 480-492. doi:10.1038/ncb3511

Khanal, I., Elbediwy, A., Diaz de la Loza Mdel, C., Fletcher, G. C. and Thompson, B. J. (2016). Shot and Patronin polarise microtubules to direct membrane traffic and biogenesis of microvilli in epithelia. J. Cell Sci. 129 2651-2659. doi:10.1242/jcs.189076

Kollman, J. M., Polka, J. K., Zelter, A., Davis, T. N. and Agard, D. A. (2010) Microtubule nucleating gamma-TuSC assembles structures with 13-fold microtubule-like symmetry. Nature 466, 879-882. doi:10.1038/nature09207

Kollman, J. M., Merdes, A., Mourey, L. and Agard, D. A. (2011). Microtubule nucleation by gamma-tubulin complexes. Nat. Rev. Mol. Cell Biol. 12, 709-721. doi:10.1038/nrm3209

Kollman, J. M., Greenberg, C. H., Li, S., Moritz, M., Zelter, A., Fong, K. K. Fernandez, J.-J., Sali, A., Kilmartin, J., Davis, T. N. et al. (2015). Ring closure activates yeast gammaTuRC for species-specific microtubule nucleation. Nat Struct. Mol. Biol. 22, 132-137. doi:10.1038/nsmb.2953

Kowanda, M., Bergalet, J., Wieczorek, M., Brouhard, G., Lécuyer, E. and Lasko, P. (2016). Loss of function of the Drosophila Ninein-related centrosomal protein Bsg25D causes mitotic defects and impairs embryonic development. Biol. Open 5, 1040-1051. doi:10.1242/bio.019638

Leong, S. Y., Yamada, M., Yanagisawa, N. and Goshima, G. (2018). SPIRAL2 stabilises endoplasmic microtubule minus ends in the moss physcomitrella patens. Cell Struct. Funct. 43, 53-60. doi:10.1247/csf.18001

Maiato, H. and Logarinho, E. (2014). Mitotic spindle multipolarity withou centrosome amplification. Nat. Cell Biol. 16, 386-394. doi:10.1038/ncb2958

Marcette, J. D., Chen, J. J. and Nonet, M. L. (2014). The Caenorhabditis elegans microtubule minus-end binding homolog PTRN-1 stabilizes synapses and neurites. Elife 3, e01637. doi:10.7554/eLife.01637

Martin, M. and Akhmanova, A. (2018). Coming into focus: mechanisms of microtubule minus-end organization. Trends Cell Biol. 28, 574-588. doi:10.1016/j. tcb.2018.02.011

Maurer, S. P., Fourniol, F. J., Bohner, G., Moores, C. A. and Surrey, T. (2012) EBs recognize a nucleotide-dependent structural cap at growing microtubule ends. Cell 149, 371-382. doi:10.1016/j.cell.2012.02.049

Merdes, A., Ramyar, K., Vechio, J. D. and Cleveland, D. W. (1996). A complex of NuMA and cytoplasmic dynein is essential for mitotic spindle assembly. Cell 87 447-458. doi:10.1016/S0092-8674(00)81365-3

Meunier, S. and Vernos, I. (2011). K-fibre minus ends are stabilized by a RanGTPdependent mechanism essential for functional spindle assembly. Nat. Cell Biol. 13, 1406-1414. doi:10.1038/ncb2372

Meunier, S., Shvedunova, M., Van Nguyen, N., Avila, L., Vernos, I. and Akhtar, A. (2015). An epigenetic regulator emerges as microtubule minus-end binding and stabilizing factor in mitosis. Nat. Commun. 6, 7889. doi:10.1038/ ncomms8889

Mogensen, M. M., Malik, A., Piel, M., Bouckson-Castaing, V. and Bornens, M (2000). Microtubule minus-end anchorage at centrosomal and non-centrosomal sites: the role of ninein. J. Cell Sci. 113 , 3013-3023.

Muroyama, A., Seldin, L. and Lechler, T. (2016). Divergent regulation of functionally distinct gamma-tubulin complexes during differentiation. J. Cell Biol. 213, 679-692. doi:10.1083/jcb.201601099

Nakamura, M., Lindeboom, J. J., Saltini, M., Mulder, B. M. and Ehrhardt, D. W. (2018). SPR2 protects minus ends to promote severing and reorientation of plant cortical microtubule arrays. J. Cell Biol. 217, 915-927. doi:10.1083/jcb.201708130

Nashchekin, D., Fernandes, A. R. and St Johnston, D. (2016). Patronin/shot cortical foci assemble the noncentrosomal microtubule array that specifies the drosophila anterior-posterior axis. Dev. Cell 38, 61-72. doi:10.1016/j.devcel.2016. 06.010

Nogales, E. and Wang, H.-W. (2006). Structural intermediates in microtubule assembly and disassembly: how and why? Curr. Opin. Cell Biol. 18, 179-184 doi:10.1016/j.ceb.2006.02.009

Noordstra, I., Liu, Q., Nijenhuis, W., Hua, S., Jiang, K., Baars, M., Remmelzwaal, S., Martin, M., Kapitein, L. C. and Akhmanova, A. (2016). Control of apico-basal epithelial polarity by the microtubule minus-end-binding protein CAMSAP3 and spectraplakin ACF7. J. Cell Sci. 129, 4278-4288. doi:10.1242/jcs.194878

Petry, S., Groen, A. C., Ishihara, K., Mitchison, T. J. and Vale, R. D. (2013) Branching microtubule nucleation in Xenopus egg extracts mediated by augmin and TPX2. Cell 152, 768-777. doi:10.1016/j.cell.2012.12.044

Prota, A. E., Setter, J., Waight, A. B., Bargsten, K., Murga, J., Diaz, J. F. and Steinmetz, M. O. (2016). Pironetin binds covalently to alphaCys 316 and perturbs a major loop and helix of alpha-tubulin to inhibit microtubule formation. J. Mol. Biol. 428, 2981-2988. doi:10.1016/j.jmb.2016.06.023
Purohit, A., Tynan, S. H., Vallee, R. and Doxsey, S. J. (1999). Direct interaction of pericentrin with cytoplasmic dynein light intermediate chain contributes to mitotic spindle organization. J. Cell Biol. 147, 481-492. doi:10.1083/jcb.147.3.481

Redwine, W. B., DeSantis, M. E., Hollyer, I., Htet, Z. M., Tran, P. T., Swanson, S. K., Florens, L., Washburn, M. P. and Reck-Peterson, S. L. (2017). The human cytoplasmic dynein interactome reveals novel activators of motility. Elife 6 e28257. doi:10.7554/eLife.28257

Richardson, C. E., Spilker, K. A., Cueva, J. G., Perrino, J., Goodman, M. B. and Shen, K. (2014). PTRN-1, a microtubule minus end-binding CAMSAP homolog, promotes microtubule function in Caenorhabditis elegans neurons. Elife 3 e01498. doi:10.7554/eLife.01498

Rivero, S., Cardenas, J., Bornens, M. and Rios, R. M. (2009). Microtubule nucleation at the cis-side of the Golgi apparatus requires AKAP450 and GM130. EMBO J. 28, 1016-1028. doi:10.1038/emboj.2009.47

Rodionov, V., Nadezhdina, E. and Borisy, G. (1999). Centrosomal control of microtubule dynamics. Proc. Natl. Acad. Sci. USA 96, 115-120. doi:10.1073/pnas. 96.1.115

Rogers, G. C., Rogers, S. L. and Sharp, D. J. (2005). Spindle microtubules in flux. J. Cell Sci. 118, 1105-1116. doi:10.1242/jcs.02284

Sánchez-Huertas, C. and Luders, J. (2015). The augmin connection in the geometry of microtubule networks. Curr. Biol. 25, R294-R299. doi:10.1016/j.cub. 2015.02.006

Sánchez-Huertas, C., Freixo, F., Viais, R., Lacasa, C., Soriano, E. and Lüders, J. (2016). Non-centrosomal nucleation mediated by augmin organizes microtubules in post-mitotic neurons and controls axonal microtubule polarity. Nat. Commun. 7 , 12187. doi:10.1038/ncomms 12187

Saunders, R. D., Avides, M. C., Howard, T., Gonzalez, C. and Glover, D. M (1997). The Drosophila gene abnormal spindle encodes a novel microtubuleassociated protein that associates with the polar regions of the mitotic spindle. J. Cell Biol. 137, 881-890. doi:10.1083/jcb.137.4.881

Schoborg, T., Zajac, A. L., Fagerstrom, C. J., Guillen, R. X. and Rusan, N. M (2015). An Asp-CaM complex is required for centrosome-pole cohesion and centrosome inheritance in neural stem cells. J. Cell Biol. 211, 987-998. doi:10. 1083/jcb.201509054

Seldin, L., Muroyama, A. and Lechler, T. (2016). NuMA-microtubule interactions are critical for spindle orientation and the morphogenesis of diverse epidermal structures. Elife 5, e12504. doi:10.7554/eLife.12504

She, Z.-Y. and Yang, W.-X. (2017). Molecular mechanisms of kinesin-14 motors in spindle assembly and chromosome segregation. J. Cell Sci. 130, 2097-2110. doi:10.1242/jcs.200261

Song, J.-G., King, M. R., Zhang, R., Kadzik, R. S., Thawani, A. and Petry, S (2018). Mechanism of how augmin directly targets the gamma-tubulin ring complex to microtubules. J. Cell Biol. 217, 2417-2428. doi:10.1083/jcb. 201711090

Steinmetz, M. O. and Prota, A. E. (2018). Microtubule-targeting agents: strategies to hijack the cytoskeleton. Trends Cell Biol. 28, 776-792. doi:10.1016/j.tcb.2018. 05.001

Tan, R., Foster, P. J., Needleman, D. J. and McKenney, R. J. (2018). Cooperative accumulation of dynein-dynactin at microtubule minus-ends drives microtubule network reorganization. Dev. Cell 44, 233-247.e4. doi:10.1016/j.devcel.2017.12. 023

Tanaka, N., Meng, W., Nagae, S. and Takeichi, M. (2012). Nezha/CAMSAP3 and CAMSAP2 cooperate in epithelial-specific organization of noncentrosomal microtubules. Proc. Natl. Acad. Sci. USA 109, 20029-20034. doi:10.1073/pnas. 1218017109

Tassin, A. M., Maro, B. and Bornens, M. (1985). Fate of microtubule-organizing centers during myogenesis in vitro. J. Cell Biol. 100, 35-46. doi:10.1083/jcb.100.1.

Tissot, N., Lepesant, J.-A., Bernard, F., Legent, K., Bosveld, F., Martin, C., Faklaris, O., Bellaïche, Y., Coppey, M. and Guichet, A. (2017). Distinct molecular cues ensure a robust microtubule-dependent nuclear positioning in the Drosophila oocyte. Nat. Commun. 8, 15168. doi:10.1038/ncomms 15168

Tovey, C. A. and Conduit, P. T. (2018). Microtubule nucleation by gamma-tubulin complexes and beyond. Essays Biochem. 62, 765-780. doi:10.1042/ EBC20180028

Toya, M., Kobayashi, S., Kawasaki, M., Shioi, G., Kaneko, M., Ishiuchi, T., Misaki, K., Meng, W. and Takeichi, M. (2016). CAMSAP3 orients the apical-tobasal polarity of microtubule arrays in epithelial cells. Proc. Natl. Acad. Sci. USA 113, 332-337. doi:10.1073/pnas.1520638113

Tungadi, E. A., Ito, A., Kiyomitsu, T. and Goshima, G. (2017). Human microcephaly ASPM protein is a spindle pole-focusing factor that function redundantly with CDK5RAP2. J. Cell Sci. 130, 3676-3684. doi:10.1242/jcs. 203703

van der Voet, M., Berends, C. W., Perreault, A., Nguyen-Ngoc, T., Gonczy, P Vidal, M., Boxem, M. and van den Heuvel, S. (2009). NuMA-related LIN-5 ASPM-1, calmodulin and dynein promote meiotic spindle rotation independently of cortical LIN-5/GPR/Galpha. Nat. Cell Biol. 11, 269-277. doi:10.1038/ncb1834

Varadarajan, R. and Rusan, N. M. (2018). Bridging centrioles and PCM in proper space and time. Essays Biochem. 62, 793-801. doi:10.1042/EBC20180036 
Wakefield, J. G., Bonaccorsi, S. and Gatti, M. (2001). The drosophila protein asp is involved in microtubule organization during spindle formation and cytokinesis. J. Cell Biol. 153, 637-648. doi:10.1083/jcb.153.4.637

Walker, R. A., O'Brien, E. T., Pryer, N. K., Soboeiro, M. F., Voter, W. A., Erickson, H. P. and Salmon, E. D. (1988). Dynamic instability of individual microtubules analyzed by video light microscopy: rate constants and transition frequencies. J. Cell Biol. 107, 1437-1448. doi:10.1083/jcb.107.4.1437

Walker, R. A., Inoue, S. and Salmon, E. D. (1989). Asymmetric behavior of severed microtubule ends after ultraviolet-microbeam irradiation of individual microtubules in vitro. J. Cell Biol. 108, 931-937. doi:10.1083/jcb.108.3.931

Wang, H., Brust-Mascher, I., Civelekoglu-Scholey, G. and Scholey, J. M. (2013) Patronin mediates a switch from kinesin-13-dependent poleward flux to anaphase B spindle elongation. J. Cell Biol. 203, 35-46. doi:10.1083/jcb.201306001

Wang, S., Wu, D., Quintin, S., Green, R. A., Cheerambathur, D. K., Ochoa, S. D. Desai, A. and Oegema, K. (2015). NOCA-1 functions with gamma-tubulin and in parallel to Patronin to assemble non-centrosomal microtubule arrays in C. elegans. Elife 4, e08649. doi:10.7554/eLife.08649

Wiese, C. and Zheng, Y. (2000). A new function for the gamma-tubulin ring complex as a microtubule minus-end cap. Nat. Cell Biol. 2, 358-364. doi:10.1038/35014051 Woodruff, J. B., Ferreira Gomes, B., Widlund, P. O., Mahamid, J., Honigmann, A. and Hyman, A. A. (2017). The centrosome is a selective condensate that nucleates microtubules by concentrating tubulin. Cell 169, 1066-1077.e10. doi:10 1016/j.cell.2017.05.028
Woodruff, J. B., Hyman, A. A. and Boke, E. (2018). Organization and function of non-dynamic biomolecular condensates. Trends Biochem. Sci. 43, 81-94. doi:10. 1016/j.tibs.2017.11.005

Wu, J., de Heus, C., Liu, Q., Bouchet, B. P., Noordstra, I., Jiang, K., Hua, S., Martin, M., Yang, C., Grigoriev, I. et al. (2016). Molecular pathway of microtubule organization at the Golgi apparatus. Dev. Cell 39, 44-60. doi:10.1016/j.devcel. 2016.08.009

Yang, J., Wang, Y., Wang, T., Jiang, J., Botting, C. H., Liu, H., Chen, Q. Naismith, J. H., Zhu, X. and Chen, L. (2016). Pironetin reacts covalently with cysteine-316 of alpha-tubulin to destabilize microtubule. Nat. Commun. 7, 12103 doi:10.1038/ncomms12103

Yang, C., Wu, J., de Heus, C., Grigoriev, I., Liv, N., Yao, Y., Smal, I., Meijering, E. Klumperman, J., Qi, R. Z. et al. (2017). EB1 and EB3 regulate microtubule minus end organization and Golgi morphology. J. Cell Biol. 216, 3179-3198. doi:10. 1083/jcb.201701024

Yau, K. W., van Beuningen, S. F., Cunha-Ferreira, I., Cloin, B. M., van Battum, E. Y., Will, L., Schatzle, P., Tas, R. P., van Krugten, J., Katrukha, E. A. et al. (2014). Microtubule minus-end binding protein CAMSAP2 controls axon specification and dendrite development. Neuron 82, 1058-1073. doi:10.1016/j. neuron.2014.04.019

Yi, P. and Goshima, G. (2018). Microtubule nucleation and organization without centrosomes. Curr. Opin. Plant Biol. 46, 1-7. doi:10.1016/j.pbi.2018.06.004

Zhang, R., Alushin, G. M., Brown, A. and Nogales, E. (2015). Mechanistic origin of microtubule dynamic instability and its modulation by EB proteins. Cell 162, 849-859. doi:10.1016/j.cell.2015.07.012 